Article

\title{
Development of an Inclined Plate Extractor-Separator for Immiscible Liquids
}

\author{
Shahid Munir ${ }^{1}$, , Syed Sheraz Daood ${ }^{1}$, Syed Zahoor ul Hassan Rizvi ${ }^{2}$ and \\ Muhammad Arif Butt ${ }^{2}$
}

1 School of Process, Environmental and Materials Engineering, University of Leeds, LS2 9JT, UK; E-Mail: daood_sheraz@yahoo.com (S.S.D.)

2 Institute of Chemical Engineering and Technology, University of the Punjab Lahore, Pakistan; E-Mails: zhrizvi@icet.pu.edu.pk (S.Z.H.R); arifbutt8@gmail.com (M.A.B.)

* Author to whom correspondence should be addressed; E-Mails: pmsm@leeds.ac.uk; shazob7@yahoo.com; Tel.: +44-79-9084-5309.

Received: 21 September 2009 / Accepted: 20 October 2009 / Published: 27 October 2009

\begin{abstract}
A new inclined plates extractor-separator is developed for operation with immiscible liquids in which extraction and separation is achieved in one unit contrary to mixer settlers. The inclined plates extractor-separator combines turbulent jets for contacting, and an inclined plate for separation of the two phases. The inclined plates extractor-separator does not have any moving part inside the vessel. This feature makes it free from the mechanical problems associated with conventional apparatus. The proposed inclined plates extractor-separator was operated in batch mode under various operating conditions to evaluate its performance on the basis of extraction efficiency. Water (light phase) was used as solvent to extract ethyl acetate from a heavy phase pool of tetrachloroethylene and ethyl acetate. The ethyl acetate content was analysed using chromatography. A hydrodynamic study was carried out using high speed photography to understand the mechanisms occurring during mass transfer across the two phases. Furthermore, it was found that the proposed inclined plate extractor-separator reduces the overall operating time by $67 \%$ and consumes only $13 \%$ of the power in comparison to a mixer-settler. A hydraulic power consumption comparison with a mixer settler and a gullwing extractor-separator is also presented.
\end{abstract}

Keywords: extraction; separation; chromatography; hydraulic power; batch mode; hydrodynamic 


\section{Introduction}

Liquid-liquid extraction is an important purification enrichment separation method used in the chemical, biochemical, petrochemical, pharmaceutical and food industries. This mass transfer operation consists of separating one or several substances (solute) present in a liquid phase by contacting it with another liquid phase in which these substances are preferentially transferred. It carries out separation by contacting a liquid feed with another immiscible liquid [1-8].

In choosing between liquid extraction and other applicable processes as a means of separation, the cost of operation as a whole is of primary concern. Liquid-liquid extraction is also significant in the area of biofuel purification. It is commonly used to separate glycerol from biodiesel, butanol from fermentation broth, and aromatics from lube oils [9-11].

Despite the increasingly extensive applications of liquid extraction, greater versatility, and the extensive amount of research that has been done, it is nevertheless a relatively immature unit operation. It is characteristic of such operations that equipment types change rapidly, new designs are being proposed frequently and last through a few applications, only to be quickly replaced by others [3,12-15]. There are many problems associated with traditional liquid-liquid extraction equipment like phase separation, solvent loss, emulsion formation, loading and flooding in conventional column contactors and mixer settlers. Moreover, traditional units also have high power consumption and are maintenance intensive due to their interior moving parts. Improving the contacting and separation performance has always been a challenge for technologists involved in developing liquid-liquid extraction equipment [16-19].

A new inclined plates extractor-separator is developed for operation with immiscible liquids in which extraction and separation is achieved in one unit, contrary to traditional mixer settlers. It is well known that effective use of turbulence can increase reactant contact and decrease reaction times because of the increased ability to transport and mixing of chemical species, added momentum, and energy as opposed to molecular diffusion alone. This can reduce the cost of operation [20-22]. A turbulent jet is a powerful tool for enhancing mass transfer at the interface between immiscible liquids due to high local rates of energy of dissipation [23-25] and plate separators are effective apparatus for the separation of dispersed feed which allows the droplets to coalesce on the inclined plate [26]. The inclined plates extractor-separator combines mass transfer through turbulent jets, which produce high relative velocities between the two phases, and separation by the inclined plate. In the current study, different operating parameters on this new proposed inclined plates extractor separator have been studied in batch mode operation. The results have also been compared with a traditional mixer settler, and a gullwing contactor which has been reported as an innovation in the literature [19] in terms of degree of extraction and power consumption for the same liquid-liquid extraction (LLE) system $[12,27,28]$.

\section{Development of the Experimental Setup and Methods}

The main components of the experimental setup, shown in Figure 1, consist of a cylindrical Perspex vessel of $0.457 \mathrm{~m}$ length and $0.3048 \mathrm{~m}$ diameter, corresponding to a volume of 33 litres. The remainder of the system includes a set of nozzles at the base of the vessel, a centrifugal pump, heavy phase storage tank, rotameter, valves for flow control, inclined plates, converging canopy, 
sample point, and a loop for light phase recirculation to the extractor-separator. The angle of inclination of the separating plate is one of the important parameters that influence the two phase flow characteristics [29].

Figure 1. Schematic diagram of the experimental rig.

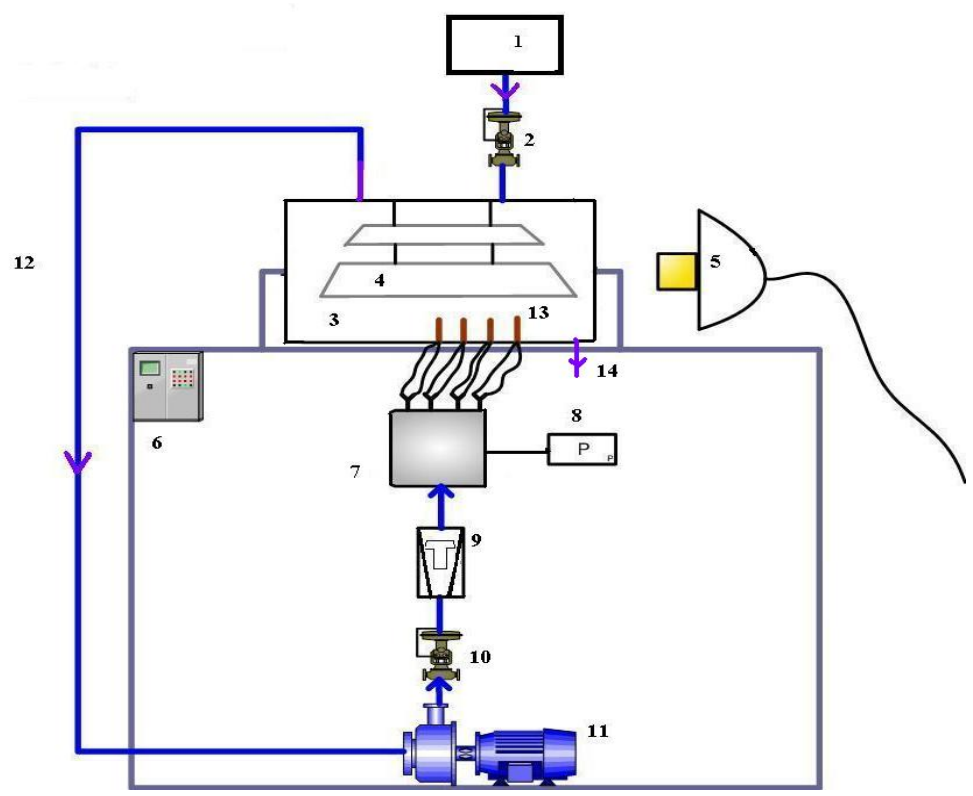

1. Heavy phase storage tank
2. Globe valve $1 / 2$ inch
3. Cylindrical vessel
4. Inclined-plates
arrangement
5. 400 watt light source

6. Control panel

7. Distributor

8. Bourdon Gauge

9. Rotameter

10. Globe valve $1 / 2$ inch

In the literature, different inclination angles for different LLE systems have been reported for two phase flow on inclined surfaces $[26,29,30]$. As extraction and separation both are taking place in one unit, inclined plate position, angle of inclination, and jetting results are mutually dependent. It has been found by Munir that $30^{\circ}$ is the optimum angle of inclination for both $4 \mathrm{~mm}$ and $5 \mathrm{~mm}$ diameter jets for the same system [31] and inclined plate extractor-separator experiments were thus performed with this plate geometry. Water and tetrachloroethylene (TCE) have quite different densities of $1 \mathrm{gm} / \mathrm{cm}^{3}$ and $1.62 \mathrm{gm} / \mathrm{cm}^{3}$, respectively. For the evaluation of the efficiency of the contactor separator, water has been used as the jetted light phase to extract ethyl acetate (EA) from the heavy phase of a tetrachloroethylene mixture (TCE/EA 95:5 on a volume basis). Total inventories of 28-30 litres of water and 4.70-6.27 litres of TCE were used for $40 \mathrm{~mm}$ and $50 \mathrm{~mm}$ pool depth experiments, respectively. For the hydrodynamic study and jet linear velocity calculations validation a FASTCAMUltima, APX high speed camera was used. The dye selected was rhodamine red because of its complete solubility only in the light phase (water). Samples were taken from the heavy phase pool at measured time intervals and analyzed for ethyl acetate content using chromatography. The samples 
were analyzed until an equilibrium concentration was achieved in the vessel. Using the equilibrium concentration the extraction efficiencies were computed for various operating conditions.

The extraction performance of the batch jet fluidized extractor-separator was evaluated using the following equation $[27,32-34]$ :

$$
\text { Degree of Extraction }(D O E)=\frac{\left(C_{i}-C_{t}\right)}{\left(C_{i}-C_{e q}\right)} \times 100
$$

where:

$$
\begin{aligned}
& \mathrm{DOE}=\text { degree of extraction }(\%) \\
& \mathrm{C}_{\mathrm{i}} \quad=\text { initial concentration of ethyl acetate }(\%) \\
& \mathrm{C}_{\mathrm{t}}=\text { concentration of EA in TCE after elapse of time }(\mathrm{t})(\%) \\
& \mathrm{C}_{\mathrm{eq}} \quad=\text { equilibrium concentration of EA in TCE }(\%)
\end{aligned}
$$

During operation, the jet of the light phase strikes the stationary heavy phase at the bottom of the contactor and accelerates it to approximately its own velocity. During the course of this acceleration the stationary heavy phase is dispersed into droplets. Liquid-liquid dispersions play an important role in the extraction process. This is because the large interfacial area, due to dispersion, aids mass transfer [35]. The heavy phase droplets are then propelled upwards by the jetted phase, producing high relative velocities between the phases, as shown in the velocity profile model (Figure 2).

Figure 2. Velocity profile model for jet flow [27-33].

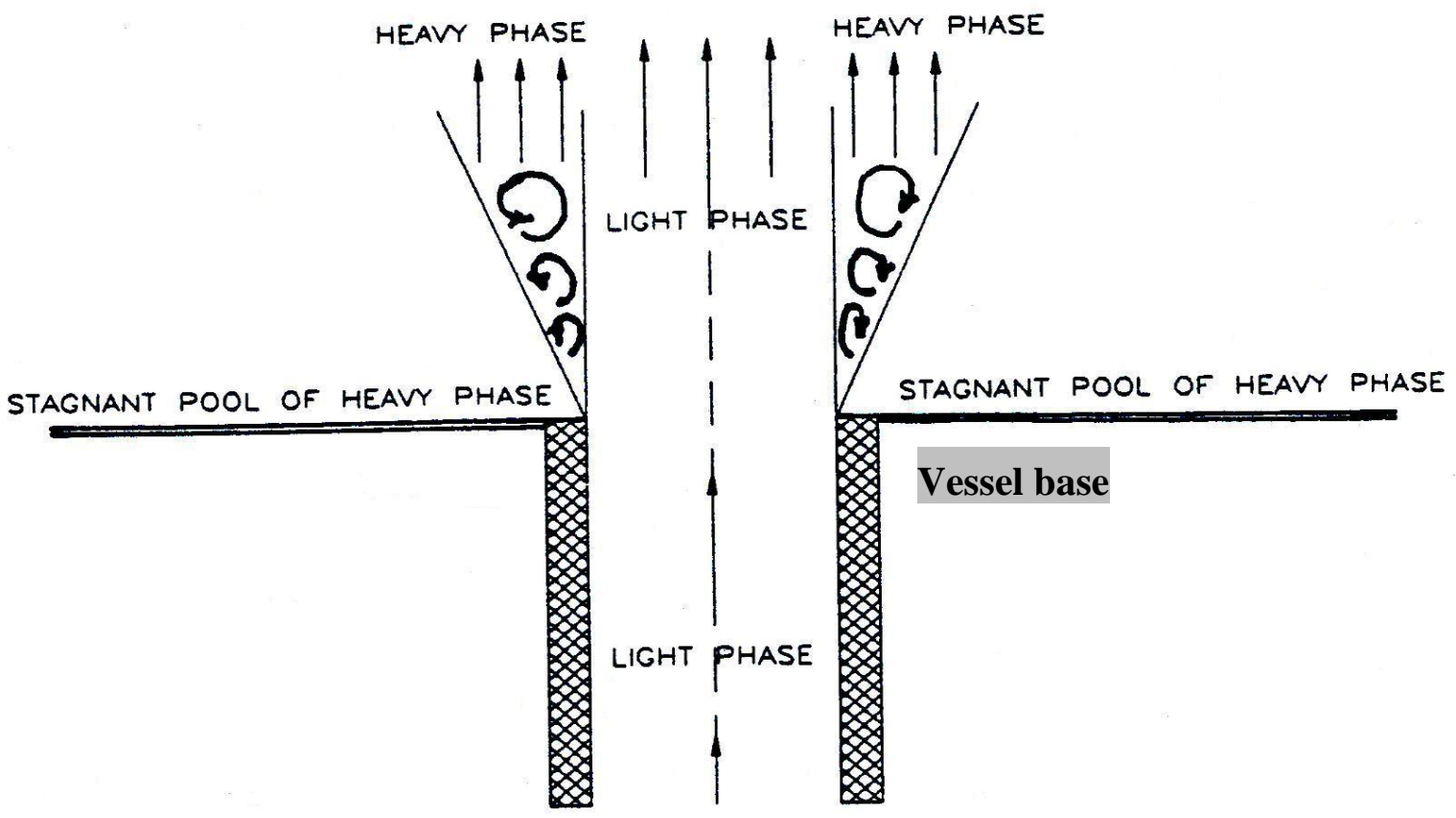

The ratio of the buoyancy force on the attenuating jet to the internal viscous force $\lambda_{\mathrm{j}}$ is termed the buoyancy parameter. With a decrease in $\lambda_{j}$ there will be an increase in the area of contact due to jet expansion and the force available at the jet exit will increase. This could lead to higher extraction efficiency [33]. The values of $\lambda_{j}$ under the conditions studied are given in Table 1.The buoyancy parameter $\lambda_{\mathrm{j}}$ is evaluated via the following equation used by Kothari [33]: 


$$
\lambda_{j}=\left[\frac{\rho_{H P}-\rho_{L P}}{\rho_{L P}}\right] \times \frac{N_{\mathrm{Re}}}{N_{F r}}
$$

where:

$$
\begin{gathered}
N_{\mathrm{Re}}=\frac{d_{N} U_{N} \rho_{L P}}{\mu_{L P}}=\frac{\text { Inertial force }}{\text { Viscousforce }} \quad(\text { Jet Reynolds Number }) \\
N_{F r}=\frac{U_{N}^{2}}{d_{N} g}=\frac{\text { Inertial force }}{\text { Gravitational force }} \text { (Jet Froude Number) }
\end{gathered}
$$

This physical phenomenon of the entrainment of the heavy phase was also observed during flow visualization studies using the high speed camera system, as shown in Figure 3.

Figure 3. Development of growing jet with entrained heavy phase droplets.

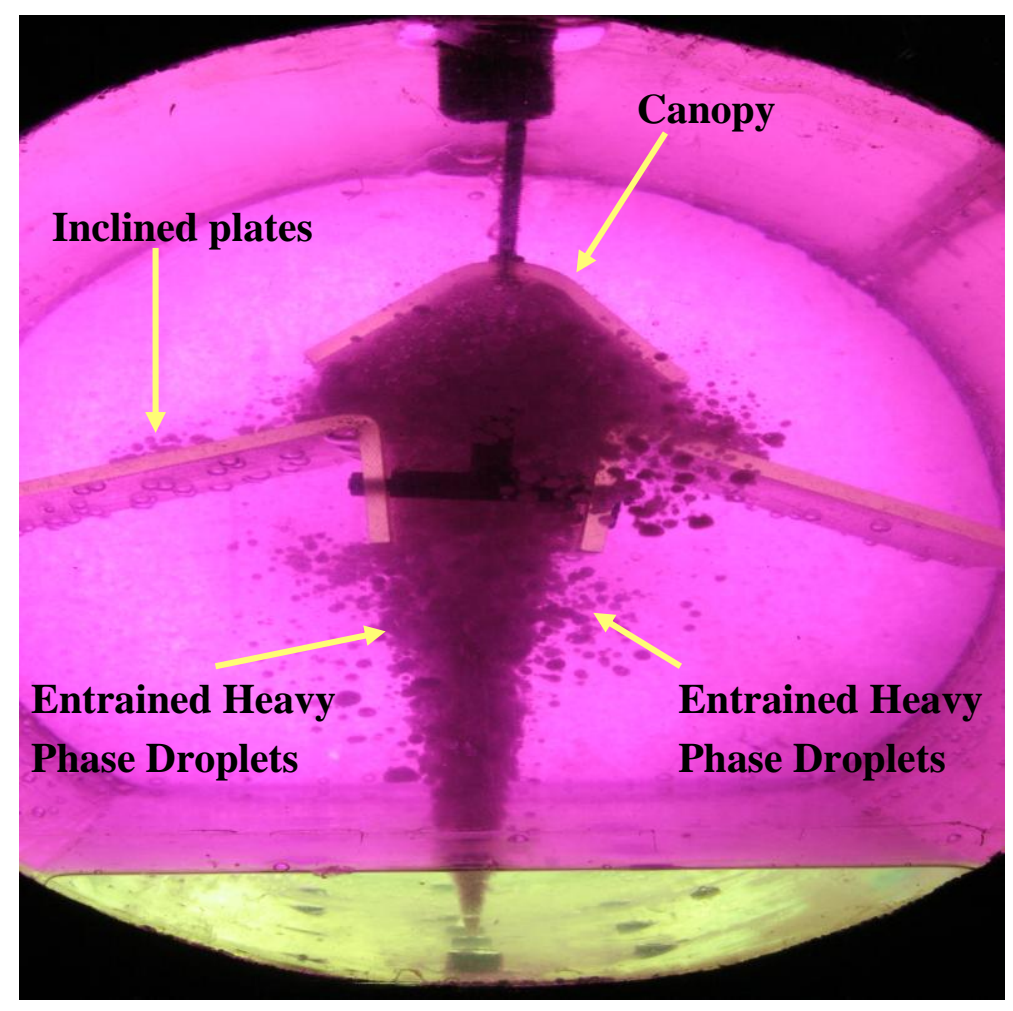

The turbulent extraction zone shown in Figure 4 is intended to produce high relative velocities between in the two liquid phases so as to accelerate the diffusion controlled extraction process. It has been observed that the entrained droplets of the heavy phase are propelled upwards by the jetted light phase towards the canopy (Figure 3), which diverges them to flow over the inclined-plates arrangement making maximum use of the available reactor volume. Here, the upward vertical motion is converted into downward inclined motion and over each half of the inclined-plates both the heavy and light phases are separated because of their density difference (primary extraction zone Figure 4). The purpose of installation of the inclined-plates arrangement is to separate the heavy phase from the light phase after extraction of the more valuable component from the heavy phase. During the upward motion through the nozzles, the light phase jet contacts the heavy phase and extracts the more valuable component depending upon its relative affinity with the light phase. In the later stage when droplets of 
both phases are brought to flow over the inclined-plates, the extraction process is simultaneously supported by separation phenomena. It has also been observed that the droplets of the heavy phase and light phase are coalesced into two films, respectively, under the influence of the shearing forces offered by the inclined-plates, the force of gravity and the component of the force of the upcoming jet. The motion of the coalesced films brings the heavy phase liquid film back to the bottom of the vessel for further contact and re-entrainment by the jetted light phase, as shown in Figure 5. Water and tetrachloroethylene have widely differing specific gravities (1.0 and 1.62 respectively), allowing fast and effective separation. The force of gravity acting on the films because of their relative density difference and the high linear velocity of the jets generates a spinning motion (Figure 2) of the heavy phase in its axial direction towards the inclined-plates arrangement so as to lead the coalesced films of both the light and heavy phases back into the turbulent zone. In the turbulent zone, further re-entrainment of the remaining more valuable component out of the heavy phase laminar pool takes place. The fresh upcoming light phase jet's velocity component along the length of the vessel propagates the light phase film towards the first deceleration zone (Figure 4). This zone is formed by the space resulting from the gap between the Inclined-plates arrangement and the rear end of the vessel, thus providing a reduction in the axial velocity of the light phase. This supports coalescence, and allows any remaining heavy phase droplets to coalesce and descend under the influence of gravity into the heavy phase pool. The samples were taken from the heavy phase bottom of this zone after measured intervals for ethyl acetate content examination using chromatography.

Figure 4. Three dimensional view of the contactor/separator.

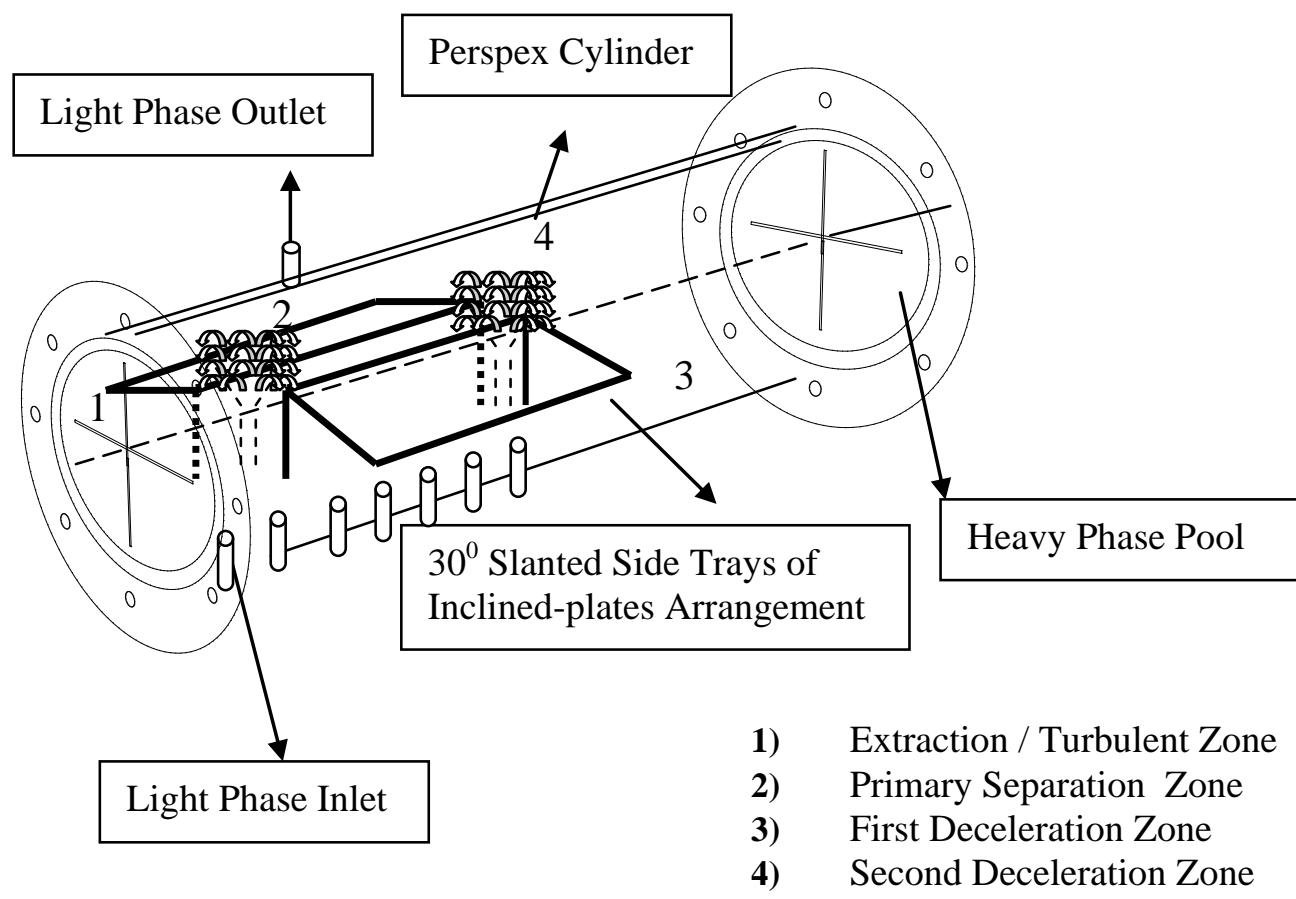


Figure 5. Motion of the coalesced films on the inclined plates while heavy phase falling back to the bottom of the vessel for further contact and re-entrainment by the jetted light phase.

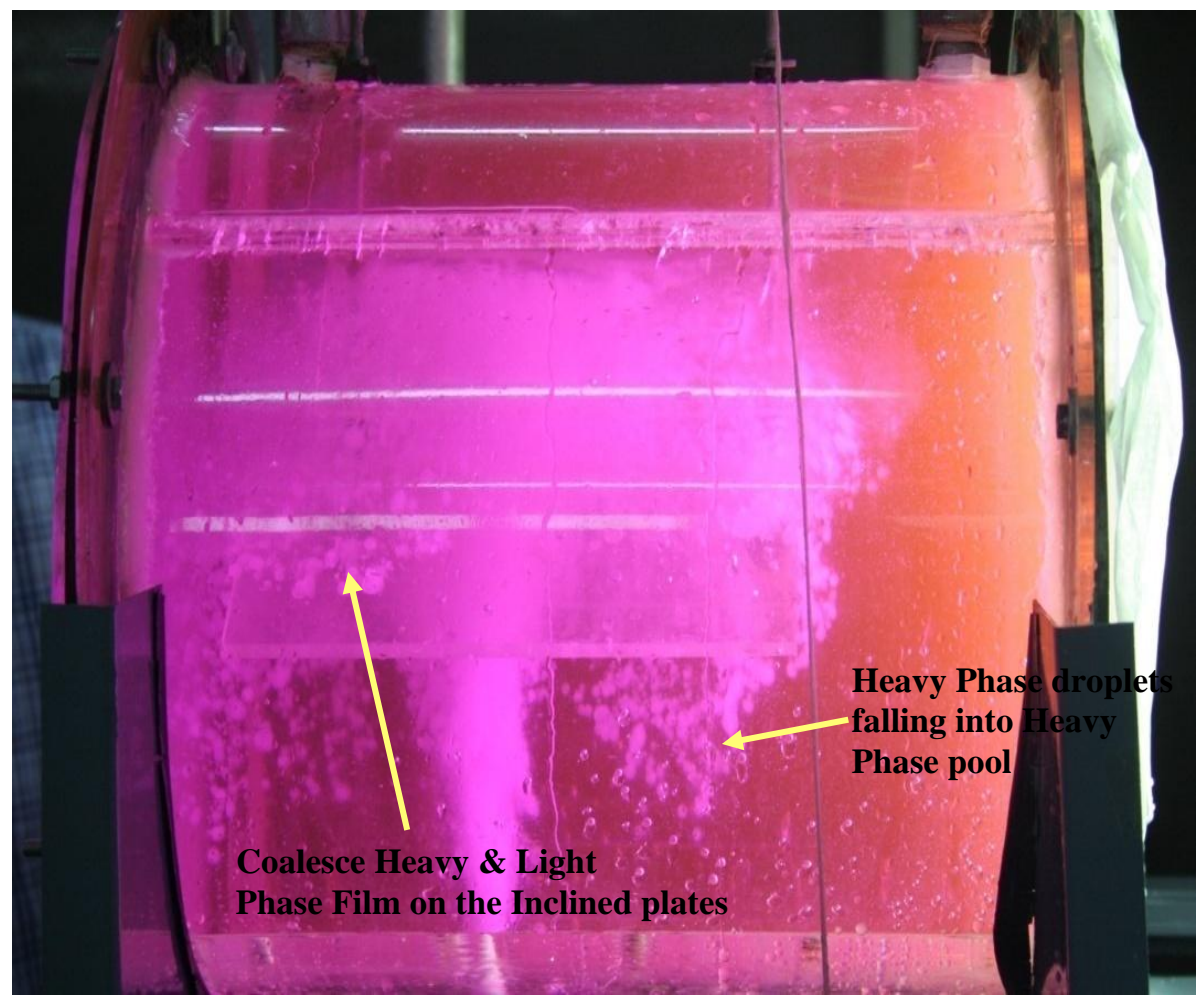

It has been found by Daood that $12.5 \mathrm{~cm}$ from the top cylindrical wall of the vessel is the optimum inclined plate position for both $4 \mathrm{~mm}$ and $5 \mathrm{~mm}$ diameter jets for the same system [36].

\section{Results and Discussions}

Degrees of extraction evaluated for the set of parameters are plotted in Figure 6. It can be seen that in the case of the $4 \mathrm{~mm}$ nozzle diameter at $50 \mathrm{~mm}$ pool depth with a single light phase jet, the degree of extraction is $62 \%$ after one minute of operation and this increases slightly. Ultimately, a degree of extraction of $87.9 \%$ is achieved after an operating time of 10 minutes. In the case of two and three light phase jets, the degrees of extraction after one minute are $64.3 \%$ and $65.7 \%$, respectively. After ten minutes, the degrees of extraction are $89.6 \%$ and $90.2 \%$, respectively. This shows that the increase in the number of light phase jet injections does not significantly increase the extraction efficiency of the system in terms of degree of extraction. The reason for this was investigated through a hydrodynamics study and it was found that in the case of $50 \mathrm{~mm}$ pool depth, the jet with $4 \mathrm{~mm}$ nozzle diameter is not so forceful $\left(\mathrm{U}_{\mathrm{N}}=2 \mathrm{~m} / \mathrm{s}, \lambda_{\mathrm{j}}=49, \mathrm{~N}_{\mathrm{Re}}=8,000, \mathrm{~N}_{\mathrm{Fr}}=102\right)$ (Table 1). Although it aided the attenuating jet to expand, while growing which increased the contact area (Figure 7), due to decreased velocity, the outer portion of the jet having heavy phase droplets spreads and a part of the fluid in it reaches its terminal velocity prior to striking the curvature of the canopy and falls down in the heavy phase pool, as shown in Figure 7, without completing the extraction process. 
Figure 6. Effect of number of light phase jets on DOE using $4 \mathrm{~mm}$ and $5 \mathrm{~mm}$ nozzles at $50 \mathrm{~mm}$ pool depth, $12.5 \mathrm{~cm}$ IPP.

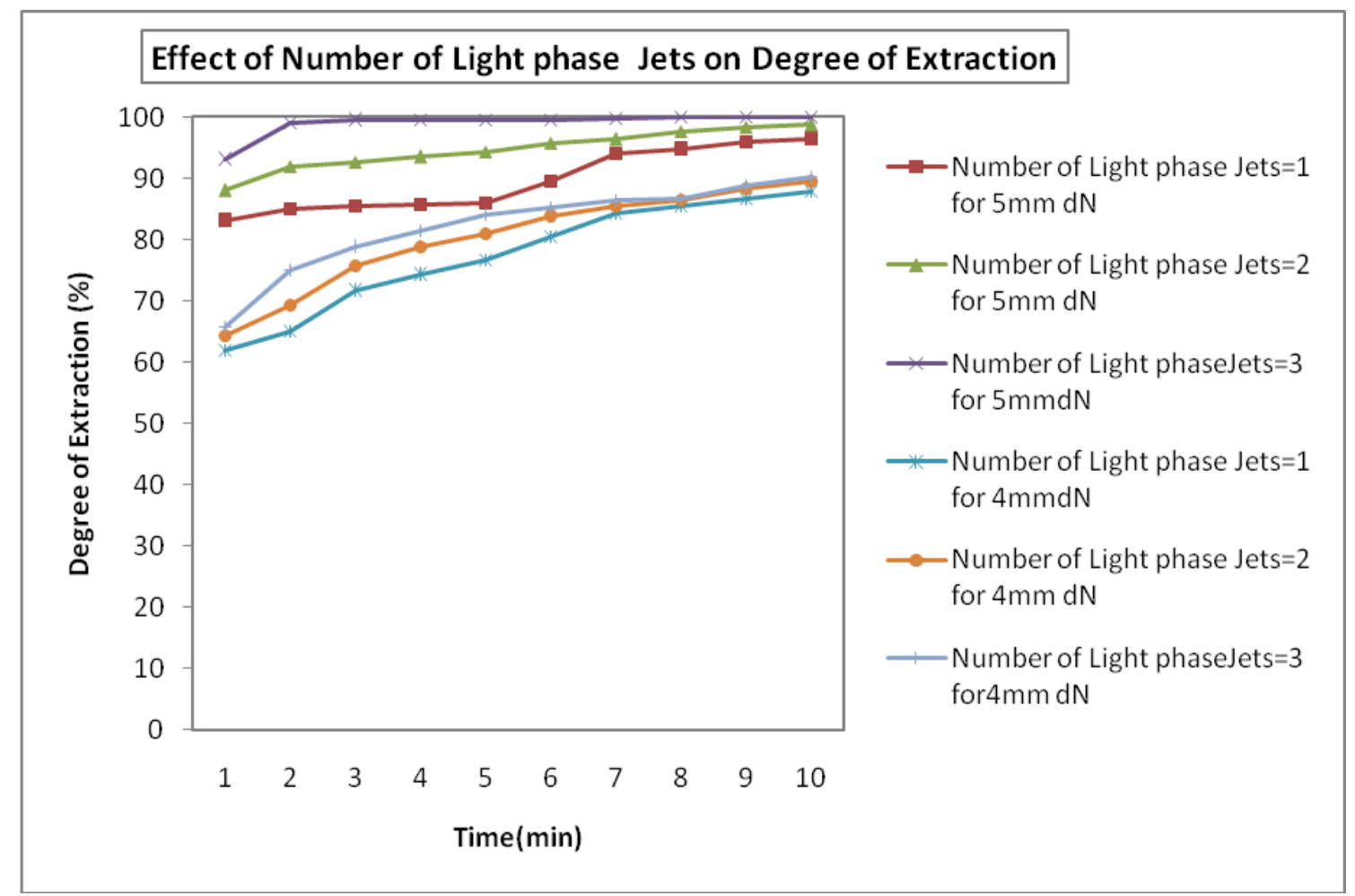

That is why the increase in degree of extraction with total operating time is not appreciable as the number of light phase jets increases. The degrees of extraction found were $87.9 \%, 89.6 \%$ and $90.2 \%$ for one, two and three light phase jets respectively. The force of the jet is decreased due to the static pressure applied by the pool of the heavy phase.

Figure 7. Hydrodynamics of $\mathrm{d}_{\mathrm{N}}=4 \mathrm{~mm}$, pool depth $50 \mathrm{~mm}$, IPP $=12.5 \mathrm{~cm}$.

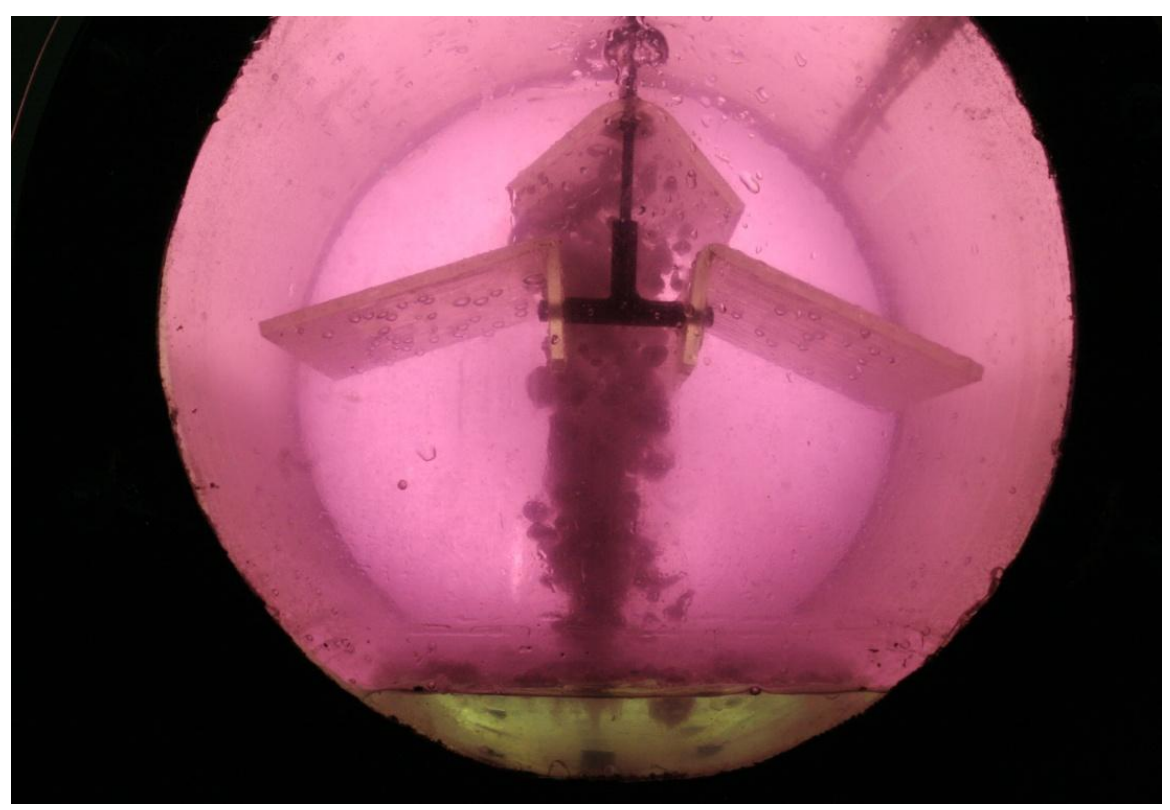


Table 1. The effect of jet linear velocity on jet Reynolds number, jet Froude number and jet Buoyancy parameter.

\begin{tabular}{|c|c|c|c|c|c|c|}
\hline \multirow{2}{*}{$\begin{array}{c}\text { Jet } \\
\text { linear }\end{array}$} & \multicolumn{2}{|c|}{$\begin{array}{c}\text { Jet Reynolds Number } \\
\mathbf{N}_{\mathbf{R e}}\end{array}$} & \multicolumn{2}{|c|}{$\begin{array}{c}\text { Jet Froude Number } \\
\mathbf{N}_{\mathbf{F r}}\end{array}$} & \multicolumn{2}{c|}{$\lambda_{j}=\left[\frac{\rho_{H P}-\rho_{L P}}{\rho_{L P}}\right] \times \frac{N_{\mathrm{Re}}}{N_{F r}}$} \\
$\mathbf{m} / \mathbf{s}$ & $\mathbf{d}_{\mathbf{N}}=\mathbf{5} \mathbf{~ m m}$ & $\mathbf{d}_{\mathbf{N}}=\mathbf{4} \mathbf{~ m m}$ & $\mathbf{d}_{\mathbf{N}}=\mathbf{5} \mathbf{~ m m}$ & $\mathbf{d}_{\mathbf{N}}=\mathbf{4} \mathbf{~ m m}$ & $\mathbf{d}_{\mathbf{N}}=\mathbf{5} \mathbf{~ m m}$ & $\mathbf{d}_{\mathbf{N}}=\mathbf{4} \mathbf{~ m m}$ \\
\hline 2.0 & 10,000 & 8,000 & 81.63 & 102 & 76 & 49 \\
2.75 & 13,750 & 11,000 & 154.3 & 193 & 55 & 35 \\
3.90 & 19,500 & 15,600 & 310 & 388 & 39 & 25 \\
4.80 & 24,000 & 19,200 & 470 & 588 & 32 & 20 \\
5.60 & 28,000 & 22,400 & 640 & 800 & 27 & 17 \\
\hline
\end{tabular}

It is quite evident from the results plotted in Figure 6 that in the case of a $5 \mathrm{~mm}$ nozzle diameter at a $50 \mathrm{~mm}$ pool depth with a single light phase jet, the degree of extraction reaches 83 percent within one minute, and gradually increases as the operation proceeds. It reaches to 96.3 percent after a time lapse of ten minutes. With two light phase jets, a degree of extraction of 88 percent is achieved just within one minute, and it gradually increases to 98.7 percent within 10 minutes. With three light phase jets, a degree of extraction of 93 percent is achieved just within a one minute time interval and it reaches 100 percent after only eight minutes of time. Samples from the light phase were analysed after the run, and carry-over was found to be below the detectable limit of $3 \mathrm{ppm}$. The reason is investigated through a hydrodynamic study and it is observed that the jet grows in the heavy phase as well as in the light phase until it strikes the inner curvature of the canopy. Then it is completely diverged on the inclined plate. The whole process occurs comprehensively and, optimum extraction takes place in the turbulent zone leading to higher mass transfer of ethyl acetate from tetrachloroethylene in to water (light phase). The jet velocity was $3.90 \mathrm{~m} / \mathrm{s}, \mathrm{N}_{\mathrm{Re}}=19,500, \mathrm{~N}_{\mathrm{Fr}}=310$ and $\lambda_{\mathrm{j}}=39$. By decreasing the buoyancy parameter, the light phase jet expansion in the heavy phase as well as in the light phase was achieved, causing an increase in the area of contact between the phases. This results in enhanced extraction efficiency. The volumetric mass transfer $\mathrm{KL}_{\mathrm{A}}$ is proportional to the square of jet velocity $\mathrm{U}^{2}{ }_{\mathrm{N}}$ jet velocity [32]. This means that at this velocity, the kinetic energy available at the nozzle exit creates the optimum turbulent contact $\left(\mathrm{N}_{\mathrm{Re}}\right)$ and interfacial area for optimum mass transfer. Further to this, entrained heavy phase droplets are fully converged on the inclined plates, forming coalesced films for separation as shown in Figure 8. The phenomenon mentioned is magnified using three light phase jets. So, when the numbers of light phase jets are increased, the same process takes place at a larger scale. An increase in number of light phase jets increases the light phase recirculation flow rate. Thus, the contacting area increases, the volume of heavy phase droplets entrained increases, which results in greater mass transfer. That is why a higher degree of extraction is achieved within very short time. 
Figure 8. Hydrodynamics of $d_{N}=5 \mathrm{~mm}$, pool depth $50 \mathrm{~mm}$ and IPP $=12.5 \mathrm{~cm}$ showing full convergence of heavy phase droplets on the inclined plates.

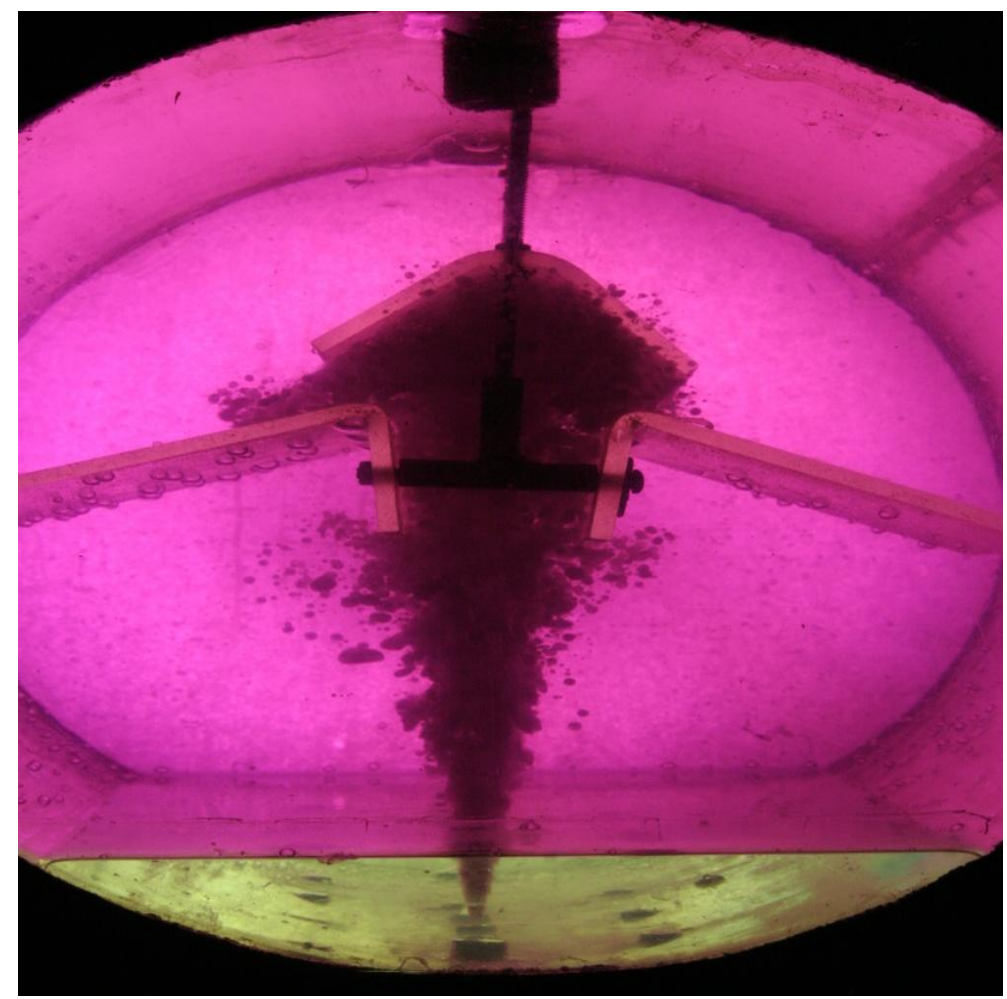

The results obtained by changing the phase ratio (by decreasing the pool depth to $40 \mathrm{~mm}$ of heavy phase with another set of operating parameters) are given in the graph shown in Figure 9.

Figure 9. Effect of number of light phase jets on DOE using $4 \mathrm{~mm}$ and $5 \mathrm{~mm}$ nozzle diameter at $40 \mathrm{~mm}$ pool depth with $12.5 \mathrm{~cm}$ IPP.

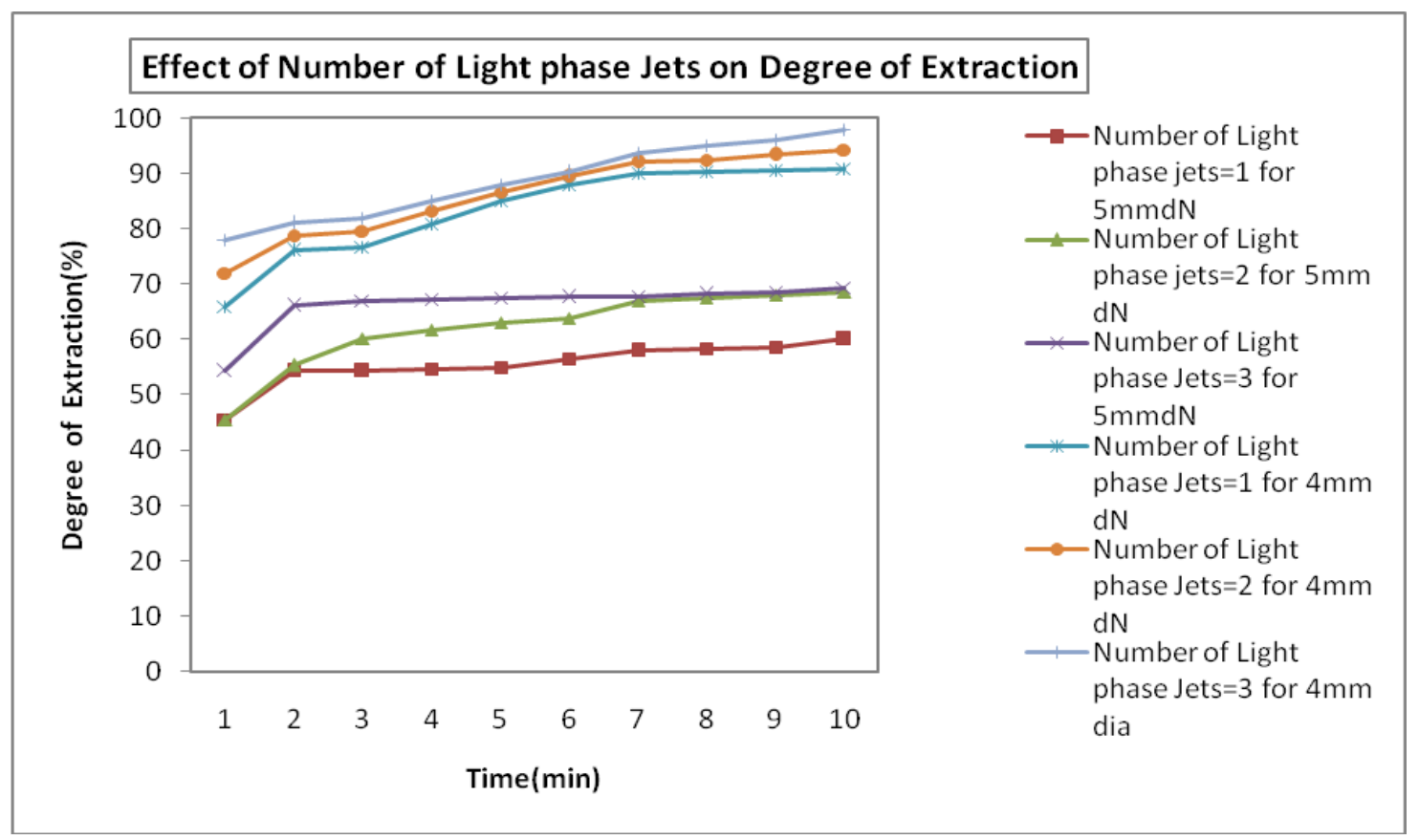


In the case of the $5 \mathrm{~mm}$ nozzle diameter with $40 \mathrm{~mm}$ pool depth, it is quite clear from Figure 9 that the degree of extraction ranges from $45.5 \%$ to $60 \%$ with a single light phase jet. For two light phase jets the degree of extraction remains between $45.5 \%$ to $68.5 \%$ for the same time lapse of 10 minutes. Similarly, for three light phase jets with $\mathrm{d}_{\mathrm{N}}=5 \mathrm{~mm}$, the degree of extraction remains between $54.3 \%$ to $69.4 \%$ for the same time lapse .This revealed that the degree of extraction does not increase as the number of light phase jets is increased from two to three. The reason, investigated through a flow visualization technique, showed the violent behaviour of the growing jet in the case of $5 \mathrm{~mm} \mathrm{~d}_{\mathrm{N}}$ and 40mm pool depth as shown in Figure 10.

Figure 10. Violent behavior of jet when $d_{N}=5 \mathrm{~mm}$, pool depth $40 \mathrm{~mm}$ and IPP $=12.5 \mathrm{~cm}$.

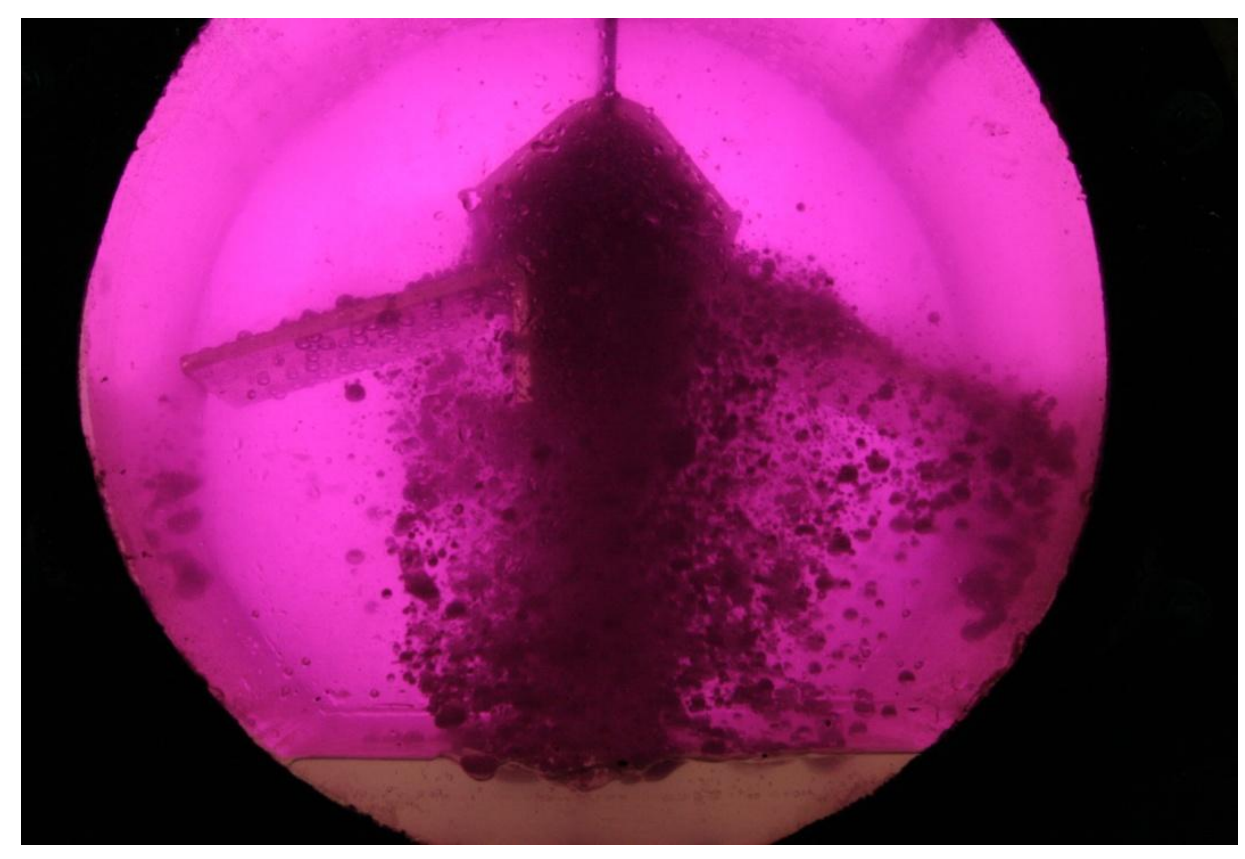

The jet strikes the inner curvature of the canopy with a high linear velocity of Un $=4.80 \mathrm{~m} / \mathrm{s}$, $\mathrm{N}_{\mathrm{Re}}=24,000, \mathrm{~N}_{\mathrm{Fr}}=470, \lambda_{\mathrm{j}}=32$ and half of it travels towards the front and rear end flanged flat circular plate of the cylindrical vessel, instead of getting diverged on the surface of the inclined plates as shown in Figure 10. When two or three jets with $d_{N}=5 \mathrm{~mm}$ at a pool depth of $40 \mathrm{~mm}$ are introduced, the same phenomenon takes place for three vibrant jets and haze formation occurs, as shown in Figure 11. For effective mass transfer, a large interfacial area must be generated between the two phases (many well dispersed small droplets); that is exactly the opposite of what is required for rapid coalescence and separation of two phases [12]. The heavy phase droplets do not coalesce to form a film on the surface of the Inclined-plate but rather act like solid spheres and no mass transfer occurs [37,38]. That is why an increase in the light phase injections has no impact on the ultimate degree of extraction. Contrary to the results with $5 \mathrm{~mm}$ nozzle diameter with $40 \mathrm{~mm}$ pool depth, it can be seen in Figure 9 that with a $4 \mathrm{~mm}$ nozzle diameter at $40 \mathrm{~mm}$ pool depth and $12.5 \mathrm{~cm}$ inclined-plates position, the degree of extraction is between 66 to 90.8 percent with a single light phase jet, while with two and three light phase injections the degrees of extraction are between 72 to 94.3 and 78 to 98 percent, respectively, for a time period of 1 to 10 minutes. Here it can be seen that maximum D.O.E with single light phase injection is $90.8 \%$, with two injections it is $94.3 \%$ and with three injections it becomes 98 percent for a time lapse of ten minutes. During the experimental runs on the rig, it is 
observed that for $40 \mathrm{~mm}$ pool depth with nozzle diameter of $4 \mathrm{~mm}$, and for $50 \mathrm{~mm}$ pool depth with $5 \mathrm{~mm}$ nozzle diameter, the process of contacting and separation is almost complete, as shown in Figures 9 and 12.

Figure 11. Haze formation at $40 \mathrm{~mm}$ pool depth, number of light phase jets $=3$, $\mathrm{d}_{\mathrm{N}}=5 \mathrm{~mm}$.

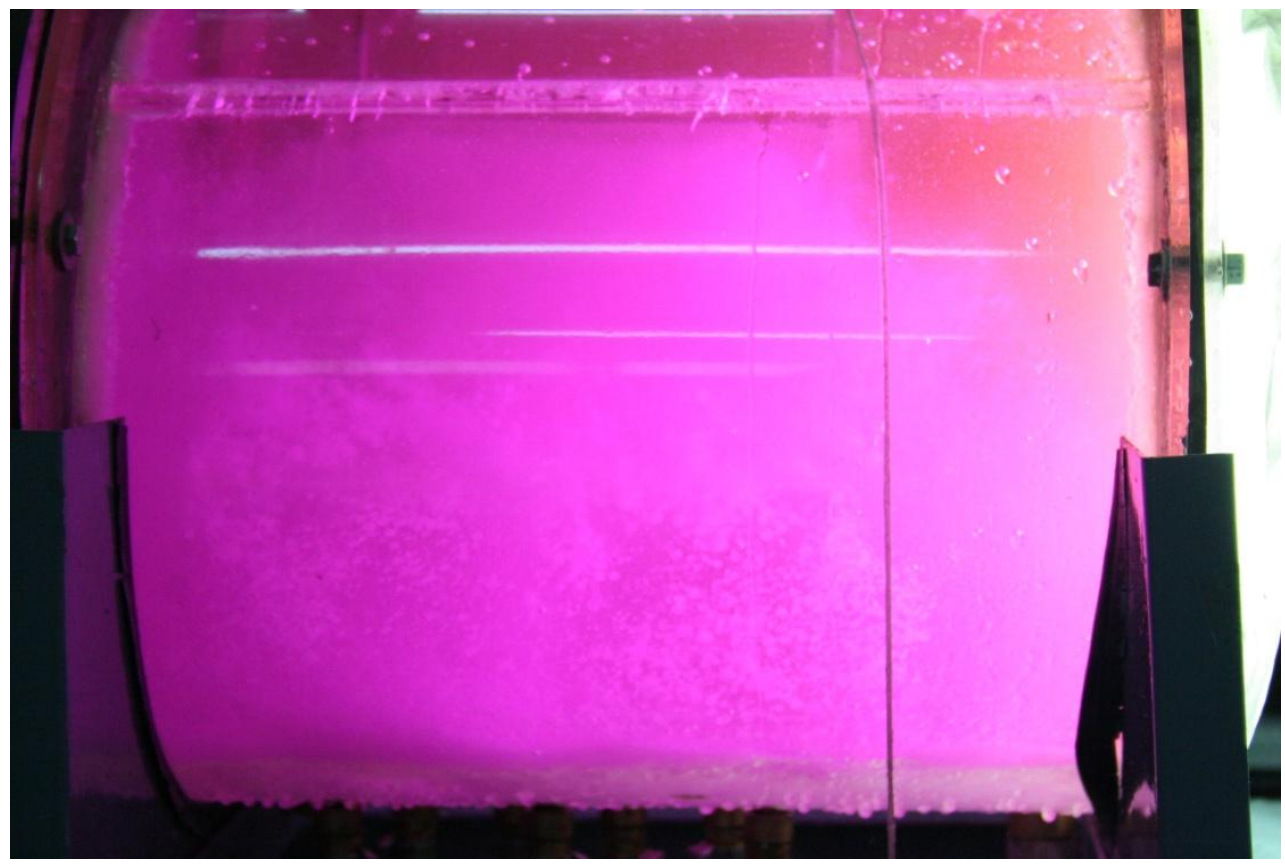

Figure 12. Effect of number of light phase jets on DOE using $5 \mathrm{~mm}$ nozzle diameter and $50 \mathrm{~mm}$ pool depths.

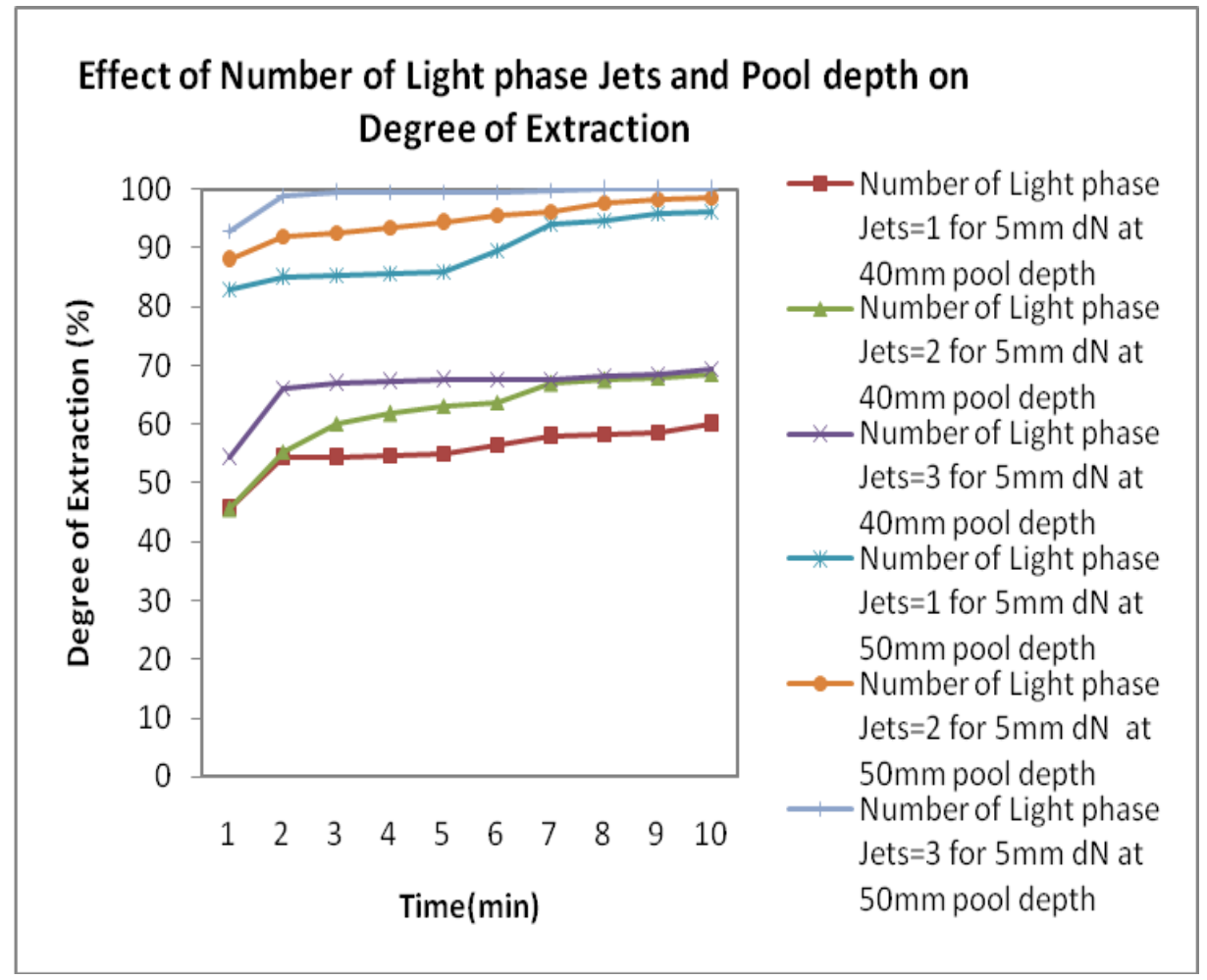


A more explanatory comparison exhibiting the effect of number of light phase jets on the degree of extraction using $5 \mathrm{~mm}$ diameter nozzle at $12.5 \mathrm{~cm}$ inclined-plate position with pool depth of $40 \mathrm{~mm}$ and $50 \mathrm{~mm}$ is given in Figures 13 and 14, which depict that an increase in the number of light phase injections with $\mathrm{d}_{\mathrm{N}}=5 \mathrm{~mm}$, increases the degree of extraction at $12.5 \mathrm{~cm}$ inclined-plate position, provided the pool depth is kept at $50 \mathrm{~mm}$ (or a phase ratio of 19:81). Otherwise, an increase in the number of light phase injections with $d_{N}=5 \mathrm{~mm}$ does not have a significant effect on the degree of extraction at the same inclined-plate position with the pool depth of $40 \mathrm{~mm}$ or at a phase ratio of 14:86. The light phase proportion includes the volume of light phase in the recirculation loop, pump and distribution box.

Figure 13. Effect of number of light phase jets and pool depths on degree of extraction using $5 \mathrm{~mm}$ nozzle diameter at $40 \mathrm{~mm}$ and $50 \mathrm{~mm}$ pool depths, $12.5 \mathrm{~cm}$ IPP. Total operating time $=10 \mathrm{~min}$.

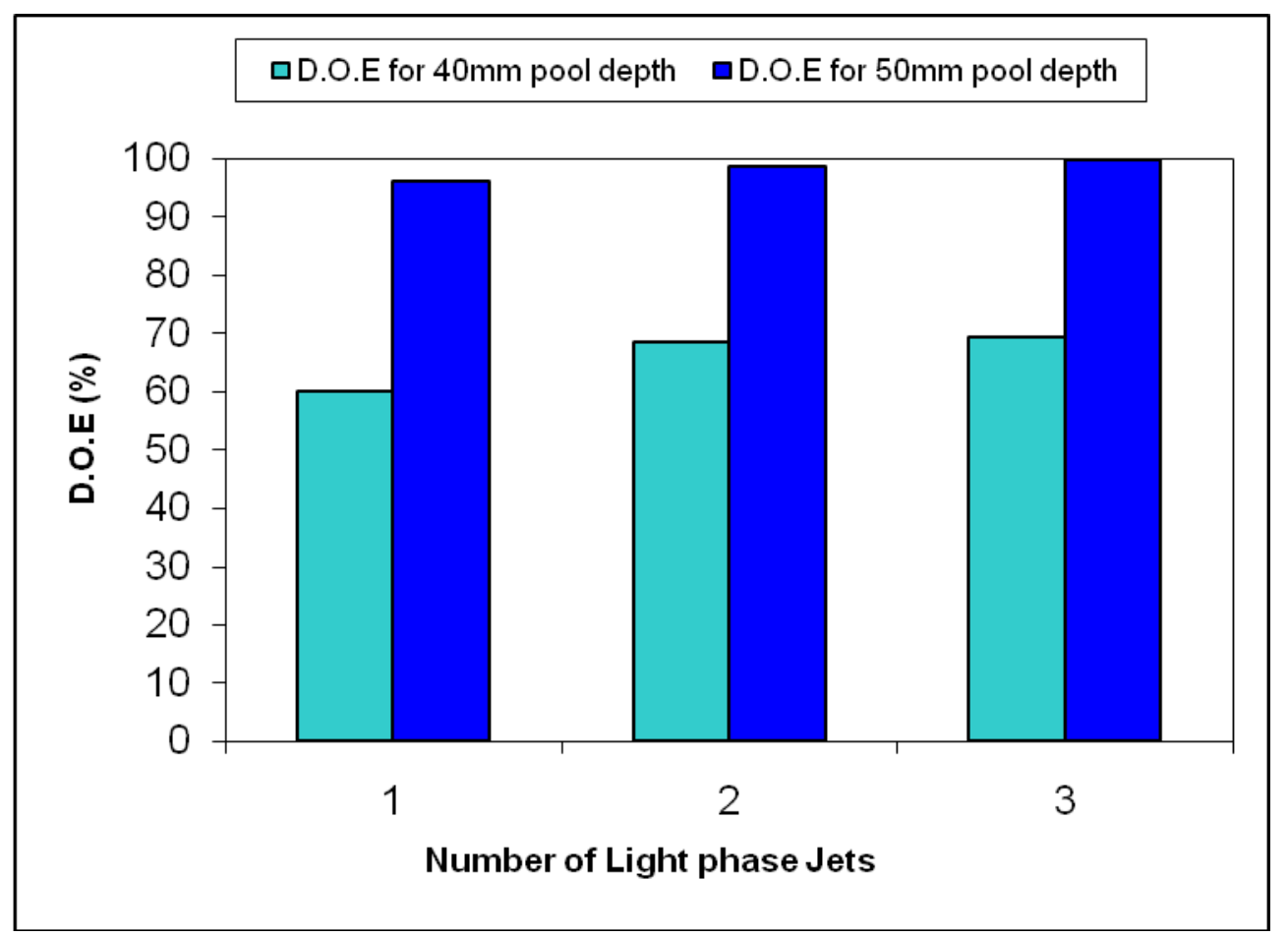

A more comprehensive comparison of the effect of number of light phase jets on the degree of extraction using $4 \mathrm{~mm}$ nozzle diameter at $40 \mathrm{~mm}$ and $50 \mathrm{~mm}$ pool depths with $12.5 \mathrm{~cm}$ inclined-plates position is shown in a bar chart given in Figure 14. This explains that in the case of $50 \mathrm{~mm}$ pool depth and $4 \mathrm{~mm}$ nozzle diameter, the increase in the number of light phase jets does not have any significant effect on the degree of extraction. On the other hand, when the pool depth is kept at $40 \mathrm{~mm}$, the degree of extraction increases with the addition of each light phase jet. 
Figure 14. Effect of number of light phase jets and pool depths on degree of extraction using $4 \mathrm{~mm}$ nozzle diameter at $40 \mathrm{~mm}$ and $50 \mathrm{~mm}$ pool depths, $12.5 \mathrm{~cm}$ IPP. Total operating time $=10 \mathrm{~min}$.

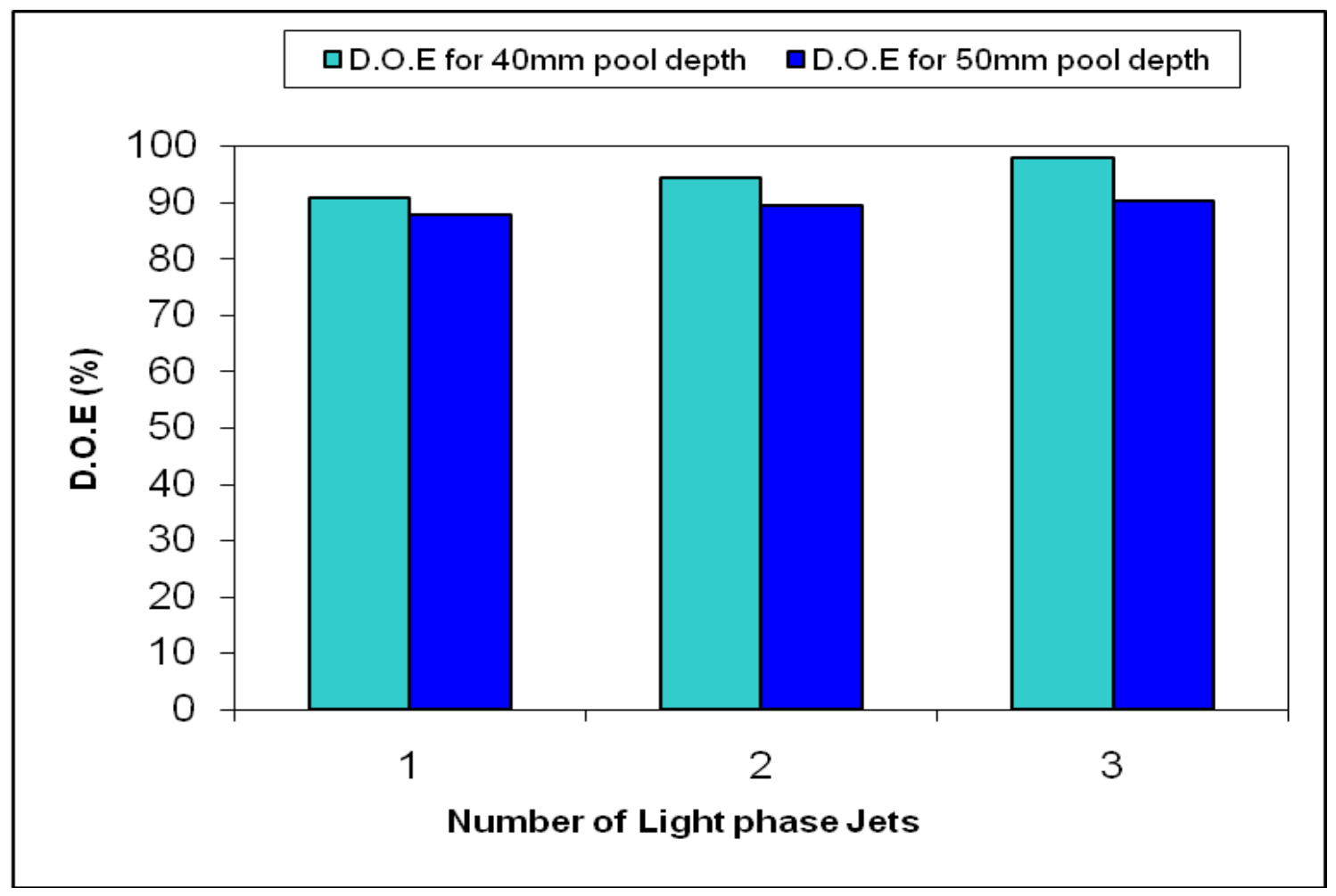

\subsection{Hydraulic Power Consumption}

The hydraulic power, which is the power input through the jet to attain a certain degree of extraction [39] in the Inclined-plate contactor ( $\left.\mathrm{h}_{\mathrm{IPES}}\right)$, can be computed using the following relation $[27,32,33,40]: h_{\text {IPES }}=\left(Q_{I P E S}\right)\left(P_{I P E S}\right) N . m / s$

The hydraulic power consumed per unit volume of extractor-separator can be calculated by using the following relation [40]:

$$
h_{I P E S}^{\prime}=\frac{\left(Q_{I P E S}\right)\left(P_{I P E S}\right)}{(1000)\left(V_{I P E S}\right)} \quad \mathrm{kW} / \mathrm{m}^{3}
$$

Table 2 given below illustrates the hydraulic power required while using optimum nozzle diameters corresponding to different pool depths.

Table 2. Hydraulic power consumption for optimum conditions.

\begin{tabular}{|c|c|c|c|c|}
\hline $\begin{array}{c}\text { Nozzle } \\
\text { diameter } \\
(\mathbf{m m})\end{array}$ & $\begin{array}{c}\text { Pool depth } \\
(\mathbf{m m})\end{array}$ & $\begin{array}{c}\text { DOE } \\
(\boldsymbol{\%})\end{array}$ & $\begin{array}{c}\text { Number of } \\
\text { Light Phase } \\
\text { Jets }\end{array}$ & $\begin{array}{c}\mathbf{h}^{\prime}{ }_{\text {IPES }} \\
\mathbf{k W} / \mathbf{m}^{\mathbf{3}}\end{array}$ \\
\hline 4 & 40 & 98 & 3 & 0.059 \\
5 & 50 & 100 & 3 & 0.12 \\
\hline
\end{tabular}


From Equation 3, it is evident that the hydraulic power consumed is directly proportional to the product of volumetric flow rate to the distributor and the pressure reading at the distributor. On the other hand, in an agitator drive system the power consumed to achieve a certain degree of extraction is directly proportional to the third power of the RPM of the agitator [41]. In a mixer settler, the whole of the contents of the mixing vessel are in motion, while in the case of the jet mixing system, only a small portion of the two phases near the jet is in motion. The conventional mixer settler operating at optimum conditions for the same EA-TCE-Water system, i.e., $400 \mathrm{rpm}$ for $99 \%$ degree of extraction consumed $0.92 \mathrm{Kw} / \mathrm{m}^{3}$ [27]. The inclined plate extractor-separator reduced the whole operating time by $67 \%$ and achieved $100 \%$ extraction. The inclined plate extractor-separator consumes only $6.4 \%$ of the power and for $98 \%$ (one percent less) degree of extraction in comparison to the $99 \%$ degree of extraction of the mixer-settler, whereas for a $100 \%$ degree of extraction (one percent above the mixer-settler's optimum degree of extraction), the inclined plate extractor-separator utilizes only $13 \%$ of the power consumed by the mixer settler. Similarly, it was also found that the proposed inclined plates extractor-separator with $4 \mathrm{~mm}$ nozzle diameter, three light phase jets with $40 \mathrm{~mm}$ pool depth requires only $0.06 \mathrm{~kW} / \mathrm{m}^{3}$ hydraulic power in comparison to the $0.11 \mathrm{~kW} / \mathrm{m}^{3}$ used by the of a gullwing extractor-separator under optimum conditions (4 mm nozzle diameter, eight jets with $40 \mathrm{~mm}$ pool depth). The investigation showed that in the gullwing extractor-separator, two $65 \mathrm{~mm}$ diameter gull wings were nominated as optimum gull wings as far as the $99 \%$ degree of extraction is concerned [42], but the area of separation in this gullwing case was only $245.16 \mathrm{~cm}^{2}$ in comparison to $464.52 \mathrm{~cm}^{2}$ separation area of the inclined-plate, so the area of separation provided in the inclined plates extractor-separator is 89 percent larger than the area of the gullwing contactor on a per unit volume basis.

\section{Conclusions}

The proposed inclined plates extractor-separator is a novel addition to the liquid-liquid extraction technology literature with respect to its design. Several parameters affecting the performance of inclined plates extractor-separator such as heavy phase pool depth, phase ratio, number of light phase jets, jet linear velocity, buoyancy factor, were investigated. It was found that the degree of extraction increases with an increase in the number of light phase jets (from 1 to 3 ) of $4 \mathrm{~mm}$ diameter from $90 \%$ to $98 \%$ at $40 \mathrm{~mm}$ pool depth (phase ratio 14:86). If the pool depth of the heavy phase is raised from $40 \mathrm{~mm}$ to $50 \mathrm{~mm}$ (phase ratio 19:81) under the same operating conditions, there is no significant effect on the degree of extraction, despite of the increase in the area of contact (increase in number of light phase jets). Similarly, for a $5 \mathrm{~mm}$ nozzle diameter the degree of extraction increases from $96 \%$ to $100 \%$ with the increase in number of light phase jets (from 1 to 3) with $50 \mathrm{~mm}$ pool depth (phase ratio 19:81) at the optimum inclined plate position. If the pool depth of heavy phase decreases from $50 \mathrm{~mm}$ (phase ratio 19:81) to $40 \mathrm{~mm}$ (phase ratio 14:86), there is no significant effect on the degree of extraction. The reasons for the stated facts were investigated through flow visualization hydrodynamics study using a high speed camera to explore the mechanisms occurring during mass transfer across two phases. Exhibited results revealed that mass transfer in this extraction-separation apparatus is linked with hydrodynamics of the attenuating light phase jet which accelerates the heavy phase and breaks it up in to dispersed coalesced droplets. The optimum configuration of the jet to 
achieve a maximum degree of extraction is dependent on the relationship between inertial force versus viscous and gravitational force (buoyancy factor). This buoyancy factor is mutually dependent on the pool depth, phase ratio, jet velocity and also on the inclined plate's position because its convergence on the inclined plate is equally important to keep the dispersed heavy phase in the region of highest relative velocities for maximizing the separation of coalesced films resulting smaller reactive volume. Furthermore, it was found that the proposed Inclined plate extractor-separator reduces the whole operating time by $67 \%$ and consumes only $13 \%$ of the power associated with the mixer-settler and requires only $0.06 \mathrm{~kW} / \mathrm{m}^{3}$ as opposed to $0.11 \mathrm{~kW} / \mathrm{m}^{3}$ for the gullwing contactor to achieve almost the same degree of extraction with same liquid-liquid extraction system. The area of separation provided in IPES is $89 \%$ larger than that for the Gullwing contactor on per unit volume basis.

\section{Nomenclature}

DOE

IPES

Extraction efficiency $(\eta)$

$\mathrm{C}_{\mathrm{i}}$

$\mathrm{C}_{\mathrm{t}}$

$\mathrm{Ceq}_{\mathrm{e}}$

IPP

$\rho_{\mathrm{LP}}$

$\mu_{\mathrm{LP}}$

$\rho_{\mathrm{HP}}$

$\mu_{\mathrm{L}}$

$\mathrm{U}_{\mathrm{N}}$

$\mathrm{d}_{\mathrm{N}}$

$h_{\text {IPES }}$

$\mathrm{h}_{\text {IPES }}^{\prime}$

QIPES

$\mathrm{P}_{\text {IPES }}$

$\mathrm{V}_{\text {IPES} \text {. }}$
Degree of Extraction

Inclined plate extractor-separator

[\%]

Initial concentration of ethyl acetate [\%]

Concentration of ethyl acetate at any time $\mathrm{t}[\%]$

Concentration of ethyl acetate at equilibrium established b/w heavy and light phases

Inclined-plate position [cm]

Density of the light phase $\left[\mathrm{gm} / \mathrm{cm}^{3}\right]$

Viscosity of light phase

Density of heavy phase $\left[\mathrm{gm} / \mathrm{cm}^{3}\right]$

Viscosity of light phase $[\mathrm{kg} / \mathrm{m} \cdot \mathrm{s}]$

Linear velocity of the jet at the nozzle exit $[\mathrm{m} / \mathrm{s}]$

Diameter of the nozzle [mm]

Hydraulic power consumption of IPES $[\mathrm{N} \cdot \mathrm{m} / \mathrm{S}]$

Hydraulic power consumed per unit volume of IPES $\left[\mathrm{kW} / \mathrm{m}^{3}\right]$

Light phase flow rate $\left[\mathrm{m}^{3} / \mathrm{s}\right]$

Gauge pressure reading $\left[\mathrm{N} / \mathrm{m}^{2}\right]$

Volume of contactor $\left[\mathrm{m}^{3}\right]$

\section{References}

1. Muthuraman, G.; Teng, T.T.; Leh, C.P.; Norli, I. Extraction and recovery of methylene blue from industrial wastewater using benzoic acid as an Extractant. J. Hazard. Mater. 2009, 163, 363-369.

2. Benis, S.G.; Hedayat, N.; Ziyari, A.; Kazemzadeh, M.; Shafiee, M. Three-dimensional simulation of hydrodynamics in a rotating disc contactor using computational fluid dynamics. Chem. Eng. Technol. 2009, 32, 93-102.

3. Okubo, Y.; Maki, T.; Aoki, N.; Khoo, T.H.; Ohmukai, Y.; Mae, K. Liquid-liquid extraction for efficient synthesis and separation by utilizing micro spaces. Chem. Eng. Sci. 2008, 63, 4070-4077. 
4. Dehkordi, A.M. Liquid-liquid extraction with chemical reaction in a novel impinging-jets reactor. AIChE J. 2002, 48, 2230-2238.

5. Monnier, N.B.; Guiraud, P.; Gourdon, C. Residence time distribution of droplets within discs and doughnuts pulsed extraction columns via Langrangian experiments and simulations. Chem. Eng. J. 2003, 94, 241.

6. Ullmann, A.; Zamir, M.; Ludmer, Z.; Brauner, N. Stratified laminar counter current flow of two liquid phases in inclined tubes. Int. J. Multiphase Flow 2003, 29, 1583-1604.

7. Nasir, S.F.; Fournier, R.L. A system for the design of optimum liquid-liquid extractant molecule. Comp. Chem. Eng. 1991, 15, 397-414.

8. Smith, R. Chemical Process Design and Integration, 1st ed.; John Wiley \& Sons: New York, NY, USA, 2005; p. 184.

9. Rahayu, S.S.; Mindaryani, A. Optimization of Biodiesel Washing by Water Extraction. In Proceedings of the World Congress on Engineering and Computer Science, San Francisco, CA, USA, October 24-26, 2007.

10. Hoseini, S.M.F.; Tavakkoli, T.; Hatamipour, M.S. Extraction of aromatic hydrocarbons from lube oil using $n$-hexane as a co-solvent. Sep. Purif. Technol. 2009, 66, 167-170.

11. Ezeji, T.C.; Qureshi, N.; Blaschek, H.P. Bioproduction of butanol from biomass: from genes to bioreactors. Curr. Opin. Biotechnol. 2007, 18, 220-227.

12. McGreavy, C.; Pitt, M.J.; Preece, P.E.; Rizvi, Z.H.; Sachs, G.E. Experimental results from Gullwing contactor/separator. In Proceedings of The IChemE Research Event, Cambridge, UK, 1991; pp. 331-332.

13. Treybal, R.E. Mass-Transfer Operations, 3rd ed.; McGraw-Hill: New York, NY, USA, 1981; pp.1, 4, 7, 8, 475, 529-530, 547.

14. Sheikh, A.R.; Ingham, J.; Hanson, C. Axial mixing in a Graesser Raining Bucket liquid-liquid contactor. Trans. I. Chem. Eng. 1972, 50, 199-200.

15. Peel, D.; Coggan, G.C. The transurface contactor; A new liquid-liquid extractor. In Proceedings of International Science Education Conference, SCI, London, UK, 1971; pp. 199-207.

16. Chan, T.Y.; Priestman, G.H.; MacInnes, J.M.; Allen, R.W.K. Development of a micro-channel contactor-separator for immiscible liquids. Chem. Eng. Res. Des. 2008, 86, 65-74.

17. Arzutug, M.E.; Yapici, S.; Kocakerim, M.M. A comparison of mass transfer between a plate and submerged conventional and multichannel impinging jets. Int. Commun. Heat Mass Transfer 2005, 32, 842-854.

18. Lin, S.H.; Juang, R.S. Mass-transfer in hollow-fiber modules for extraction and back-extraction of copper (II) with LIX64N carriers. J. Membr. Sci. 2001, 188, 251-262.

19. Hewitt, G.F. Chemical Engineering in the British ISLES: The academic sector. Chem. Eng. Res. Des. 1991, 69, 79-90.

20. Feng, H.; Olsen, M.G.; Liu, Y.; Fox, R.O.; Hill, J.C. Investigation of Turbulent Mixing in a confined planar-jet reactor. AIChE J. 2005, 51, 2649-2664.

21. Forney L. J.; Nafia, N. Turbulent jet reactors: Mixing time scales. Trans. I. Chem. Eng. 1998, 76, 728-736.

22. Forney, L.J.; Nafia, N.; Vo, H. X. Optimum jet mixing in a tubular reactor. AIChE J. 1996, 42, 3113-3122. 
23. Sedahmed, G.H.; Abdo, M.S.; Hassan, M.S.; Konsowa A.H. Intensification of mass transfer controlled processes at the interface between two immiscible liquids by an axial turbulent submerged jet. Chem. Eng. Process. 2007, 46, 10-16.

24. Baldyga, J.; Broune, J.R.; Gholap, R.V. The influence of viscosity on mixing in jet reactors. Chem. Eng. Sci. 1995, 50, 1878-1880.

25. Baldyga, J.; Bourne, J.R.; Zimmermann, B. Investigation of mixing in jet reactors using fast, competitive-consecutive reactions. Chem. Eng. Sci. 1994, 49, 1937-1946.

26. Rommel, W.; Blass. E.; Meon, W. Plate separators for dispersed liquid-liquid systems: Multiphase flow, droplet coalescence separation performance and design. Chem. Eng. Sci. 1992, 47, 555-564.

27. Rizvi, Z.H. Hydrodynamics of liquid-liquid extraction processes in the gullwing contactor. Ph.D. Thesis, University of Leeds: Leeds, UK, 1990.

28. Kothari, D.; Pitt, M.J; Sachs, G.E. Application of gullwing contactor for liquid-liquid extraction. In Proceedings of the IChemE Research Event, University College London, London, UK, 5-6 January, 1994; pp. 819-822.

29. Ullmann, A.; Zamir, M.; Gat, S.; Brauner, N. Multi-holdups in co-current stratified flow in inclined tubes. Int. J. Multiphase Flow 2003, 29, 1565-1581.

30. Rodriguez, O.M.H.; Oliemans, R.V.A. Experimental study on oil-water flow in horizontal and slightly inclined pipes. Int. J. Multiphase Flow 2006, 32, 323-343.

31. Munir. S. To study the effect of number of light phase injections corresponding to different phase ratio on the degree of extraction in an inclined plates extractor/separator aided with hydrodynamic study. M.Sc. Thesis, University of the Punjab: Lahore, Pakistan, 2007; pp. 77-114.

32. Chang, H.Y. Hydrodynamics of liquid-liquid extraction in the gullwing contactor. Ph.D. Thesis, University of Leeds: Leeds, UK, 1995.

33. Kothari, D. Application of gullwing contactor for liquid-liquid extraction. M.Phil. Thesis, University of Leeds: Leeds, UK, 1994.

34. Rizvi, Z.H.; Preece, P.E.; McGreavy, C.; Sachs, G.E. Turbulent liquid jets in immiscible liquid systems. J. PI ChE. 1990, XIV-XVIII, 15-33.

35. Ban. T.; Kawaizumi, F.; Nii. S.; Takahashi, K. Study of drop coalescence behaviour for liquid-liquid extraction operation. Chem. Eng. Sci. 2000, 55, 5385-5391.

36. Dawood, S.S. To study the effect of inclined plate position and nozzle diameter corresponding to different phase ratio on the degree of extraction in an inclined plates extractor/separator aided with hydrodynamic study. M.Sc. Thesis, I.C.E.T, University of the Punjab: Lahore, Pakistan, 2007; pp. 95-109.

37. Skelland, A.H.P.; Minhas. S.S. Dispersed Phase Mass Transfer during drop formation and coalescence in liquid-liquid extraction. AIChE J. 1971, 17, 1316-1324.

38. Davies, J.T. Turbulance phenomena. Academic Press: New York, NY, USA, 1972; pp. 62-76, 327-363.

39. Patwardhan, A.W.; Thatte, A.R. Process design aspects of jet mixers. Can. J. Chem. Eng. 2004, 82, 198-205.

40. Rizvi, Z.H.; Preece, P.E.; McGreavy, C.; Sachs, G.E. Development of a novel mini-hydrocyclone contactor/separator. J. PI ChE. 1994, XXII, 8-9. 
41. Rushton, J.H.; Costich, E.W.; Everett, H.J. Power characteristics of mixing impellers. Chem. Eng. Prog. 1950, 46, 395-404.

42. Rizvi, Z.H.; Preece, P.E.; McGreavy, C.; Sachs, G.E. Design of novel jet system using gullwings. J. PI ChE. 1993, XXI, 27-44.

(C) 2009 by the authors; licensee Molecular Diversity Preservation International, Basel, Switzerland. This article is an open-access article distributed under the terms and conditions of the Creative Commons Attribution license (http://creativecommons.org/licenses/by/3.0/). 